\title{
A Total Quality Management Approach To Assurance Of Learning In The Accounting Classroom: An Empirical Study
}

Mary Ellen Harvey, Ramapo College of New Jersey, USA Susan Eisner, Ramapo College of New Jersey, USA

\begin{abstract}
The research presented in this paper seeks to discern which combination of pedagogical tools most positively impact student learning of the introductory Accounting curriculum in the Principles of Accounting courses in a 4-year U.S. public college. This research topic is relevant because it helps address a quandary many instructors experience: how to teach quantifiable courses in a way that resonates with and reaches undergraduate business students. The significance is underscored by concerns that U.S.-educated students lack quantitative ability needed in the $21^{\text {st }}$ century workplace, and is heightened all the more by uncertainties in the current economic climate that would seem to make quantitative competencies all the more vital. Toward that end, student perceptions of course delivery methods were analyzed at the conclusion of the first of a two-course sequenced introductory Accounting course. The results were used to redesign the second half of the course, after which measured perceptions were compared with actual outcomes. Results and proscriptions for advancing Principles of Accounting course pedagogy are presented.
\end{abstract}

Keywords: Teaching Methods; Accounting Pedagogy; Total Quality Management; Assurance of Learning

\section{INTRODUCTION}

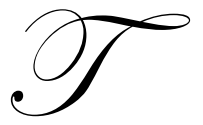

he goal of this research is to extend the application of Total Quality Management (TQM) philosophy, which was initially introduced to and subsequently embraced by the business world, to the classroom environment. TQM aims to optimize goal attainment through customer satisfaction, continuous improvement, empowerment and teamwork (Leigh, 1995). Workplace implementation of those TQM cornerstones have provided businesses with increased efficiency, effectiveness and employee morale. Business schools have long since implemented TQM into their curricula; TQM theory and practice are a staple of Management textbooks. Applying TQM to classroom management is a natural and logical way to assure student learning by advancing teaching methods based on data reporting on their effectiveness - what schools seeking accreditation from the toptier business school accrediting body, AACSB International, refer to as "closing the loop" (Martell, 2007; Stivers and Phillips, 2009; Zhu and McFarland, 2005).

\section{BACKGROUND}

Business schools can integrate TQM into their curricula on two tracks: by teaching the theory to students, and by applying the theory to administering classrooms and departments. Possible resistance by some academicians, who may relish autonomy inherent in their positions or reflect teaching methods by which they were instructed as students, may well break down as business school case studies evidence great success with including students in the process. In addition, industry isn't backing off in their demand for better prepared graduates. Their concerns are underscored by reports that U.S.-educated students lack quantitative ability needed in the $21^{\text {st }}$ workplace (CasnerLotto and Wright, 2009), and is heightened all the more by uncertainties in the current economic climate that would seem to make quantitative competencies all the more vital. 
Just as businesses have successfully used TQM principles to gain a competitive advantage in producing products or services, (Pakdil, 2010) so too can instructors use it to improve their yield ratio. In the case of instructors, the output is a better prepared student where the inputs (i.e. teaching techniques and tools) are theoretically limitless. Instructors and students would seem to have a common interest in continually pursuing the inputs which are most effective in increasing their learning.

Plentiful research on learning styles clearly shows each student benefits from a targeted combination of educational tools that resonate individually (Levine, 2002). Ideally, each student would be able to personally design a course to maximize their learning. Given the impracticality of this in most situations, a step in this direction can be taken by empowering the class as a whole to have a more direct say in their learning process. This philosophy is basic to TQM, and so therefore, application of TQM techniques to a classroom seems like a natural fit.

\section{LITERATURE REVIEW}

American-born W. Edwards Deming is considered the father of TQM (Gershon, 2010). His groundbreaking series of lectures and training on quality control in the 1950's popularized TQM within the Japanese manufacturing sector (Noguchi, 1995). Since then, the importance of injecting Deming's cornerstones of quality at every production and service level has permeated throughout the world and inspired the application of TQM core concepts in many fields, including education. Regional, national, and international accrediting bodies in the field of education support development and application of assessment methods that have continuous improvement in student learning at their core (Mundhenk, 2005). AACSB-accredited business schools, for example, must meet an assurance of learning standard. The Eligibility Procedures and Accreditation Standards for Business Accreditation states, "Learning goals should be set and revised at a level that encourages continuous improvement in educational programs" (Association to Advance Collegiate Schools of Business, 2006, p. 57).

An initial examination of the TQM literature deemed relevant to the current study revealed various tracks of research, and clearly documented the broad reach of Deming's work. Specifically, the existing literature regarding TQM's educational usage can generally be grouped into four categories: the application of TQM to the administration of education programs (Meirovich and Romar, 2006; Venkatraman, 2007); Assurance of Learning in higher education (Betters -Reed et al., 2008; Martell, 2007); teaching Accounting, in particular teaching the Principles of Accounting courses (Lavoie and Rosman, 2007; Phillips and Phillips, 2007); and finally, most directly related to this paper's work, TQM applied in the college classroom.

Within the last category, two sub-categories of research were identified. The first applies TQM theories in the context of a single-semester class, often starting with inviting students to help develop course materials (Brown and Murti, 2003; Durlabhji and Fusilier, 1999; Peters et al., 2005; Potocki et al., 1994). The second set of research in this area more loosely adopts a TQM approach and reports on using more detailed student feedback to improve future course delivery (Al-Shammari, 2005; Sakthivel and Raju, 2005). McConnell et al., (2008), argue that many of the assessment tools used by colleges to meet the AACSB accreditation standard, while providing general information, do not provide enough specific feedback to help an instructor improve the delivery of a particular course. It is in this area of micro-course feedback that there appears to be a gap in the literature, thus providing motivation for the current study.

\section{CROSSOVER TO EDUCATION: CONTROVERSIES}

The basic tenets of TQM helps explain some of the challenges related to integrating TQM into the classroom either within a single-semester course or for the purpose of improving future courses. TQM defines quality as delivering a product or service meeting or exceeding customer expectation; quality, thus, is subjectively defined by the customer whose definition of quality the provider of the goods or services seeks to objectively determine (Ross, 1995). When applied to education, a complex and controversial question arises: is the student a "customer" to whom learning is delivered or is the learned student the product delivered? Venkatraman (2007) regards the students as the primary external customers, while Manivannan and Premila (2009) propose that the product is not the student but the "learning of the student". They promulgate the belief that the teacher and student create a team that together should participate in the process of assuring student learning. 
Regardless of how the student and product are defined, integrating TQM into the classrooms also requires a 'buy-in' from faculty. Resistance often occurs at this level because instructors may be fearful of, and/or misinterpret what exactly 'empowering' the students' means. For example, Walker (1995) indicates that faculty members often believe a shift to branding the student as a customer would result in the students defining course content. However, a survey of teachers who participated in a large (739 students) 'TQM in the classroom' pilot study cited many benefits, including increases in student learning responsibility, improved grades and enthusiasm, positive studentteacher relationships, and less teacher stress (Leigh, 1995). Although the practice of monitoring and measuring educational value has become more widespread and can generate enthusiasm among faculty, asking teachers to rethink their pedagogical delivery methods can still represent a formidable challenge (Venkatraman, 2007).

\section{RESEARCH DESIGN}

The goal of the study presented in this paper is to take the first step in applying TQM to a classroom by measuring student input regarding what they (as customers) need to learn better, and measuring those perceptions of quality with actual learning achieved. This study was conducted at a 4-year public college in New Jersey, in a twocourse sequenced introduction to Accounting curriculum.

The study occurred in stages. At the end of the first of a two-course sequenced Principles of Accounting class, student perceptions of course delivery methods were intentionally analyzed through primary data collected specifically for the purpose of this study. A questionnaire survey was designed to measure the students' perceptions of how the various course delivery tools helped them with the overall learning process in the Accounting 1 class. As the instructor and specific class participants for the second sequenced course (Accounting 2) were expected to remain relatively unchanged, studying these two linked courses presented an ideal opportunity to solicit input, adjust pedagogical delivery, and then measure the results.

The survey was administered at the end of the first semester (Principles 1) and asked students to consider how 19 different learning tools impacted their overall learning process in the class. The list was developed subjectively by the authors based on a review of course materials and resources used during the semester in teaching the class. Respondents were asked to identify the relevance of the delivery tools via both a numerical, horizontal scale and a forced-rank scale.

Sixty-two surveys were completed, with most (58) being fully usable. The unusable ones were due to unfinished demographics, or seeming confusion over the ranking scale. Descriptive statistical techniques were used to analyze the survey data. A thorough review of the resulting data and handwritten responses to open-ended questions was conducted.

As a result of this review, pedagogy for the second course, Principles of Accounting 2, was re-designed to reflect the results and establish a basis for the second half of the research. The objective of the second half of the research was to measure whether student perceptions were in congruence with independently measured results. Specifically, the results of the student perception survey were used to create a matrix for the second course to coordinate the course topics and the various delivery tools used to deliver the course content.

Student performance in each topic area was then measured via embedded multiple choice test questions. This method of measurement was chosen as it was perceived to be objective and was supported by prior research (McConnell et al., 2008). Three tests encompassing different subject matter were given during the semester, and results were analyzed after each one in order to decide how to apply delivery aides to the subsequent course topics.

\section{Sample Selection and Demographics}

For both semesters a convenience sample was used. Two sections, per semester, of the same course were chosen (in total, four sections over two consecutive semesters were examined). All four sections were taught by the same instructor. Basic demographic information was obtained from the students in both semesters in order to better understand the nature of the sample characteristics, identify any significant differences in the study participants, and help interpret the results. The demographics collected for each respondent were gender, age, overall GPA and current course anticipated GPA. 


\section{MEASUREMENT OF VARIABLES}

\section{Horizontal, Numerical Scale Survey}

Students were asked to rank 19 learning 'mechanisms' according to their importance in the students' learning process. Each of the items were based on pedagogical tools that had been available to the students in the current semester (e.g. tutoring services) or requirements they had been exposed to (e.g. turning their homework in to the teacher).

A horizontal numeric scale produces rankings and equal interval data for statistical analysis (Alreck and Settle, 1985). For the purpose of this study the Mean, Mode, Sample Standard Deviation, Maximum and Minimum were measured and analyzed. The exploratory nature of this research was the motivation behind gathering as much data as possible. A Likert scale was used and the intermediate points on the scale were not labeled, as research suggests this may actually result in undesirable data (Alreck).

\section{Forced Rank Scale}

Students were also asked to rank the top five items of the 19 available, which were the same items listed in the Horizontal scale. Alreck and Settle (1985), suggest limiting the number of items to be ranked to under 10. An advantage to using a forced rank scale in addition to a Likert scale, is it "forces" the respondent to think of each item in relation to the others and thus make a deliberate choice.

\section{Written Responses}

Direct input was also solicited from the students, by means of directed responses and an open-ended question. Specifically, students were asked to provide additional written information regarding processes or techniques that would add to their learning experience and/or provide any other commentary on the subject.

\section{RESULTS}

\section{Demographics}

The demographics were analyzed between the two semesters (Table 1). The second half of the study had $14(24 \%)$ more participants, were slightly younger and included more males. There were also more students with a declared quantitative-oriented major (Finance or Accounting). Overall, the sample constituents were not identical, but appear to be comparable for the purposes of the current study.

Table 1

Summary of Demographics

\begin{tabular}{|l|l|l|}
\hline & \multicolumn{1}{|c|}{ Principles 1 } & \multicolumn{1}{|c|}{ Principles 2 } \\
\hline Number of respondents (n) & 58 & 72 \\
\hline Gender & $59 \%$ male & $66 \%$ male \\
& $41 \%$ female & $34 \%$ female \\
\hline Age & $89 \% 22$ yrs or younger & $96 \% 22$ yrs or younger \\
\hline Major & $22 \%$ Finance & $26 \%$ Finance \\
& $20 \%$ Accounting & $25 \%$ Marketing \\
& $19 \%$ Marketing & $23 \%$ Accounting \\
& $13 \%$ Management & $16 \%$ Management \\
& $9 \%$ Economics & $4 \%$ Economics \\
& $6 \%$ Info systems & $3 \%$ Info systems \\
& $6 \%$ Undeclared & $3 \%$ Other \\
& $5 \%$ International Bus/Other & $0 \%$ IB/ Undeclared \\
\hline
\end{tabular}




\section{Development of Treatment Variables}

The survey questionnaire resulted in 58 usable surveys. The top five and bottom five learning aides (as ranked by the participants) were identified and are listed in Table 2. There were three common elements within the two scales: class lectures, reviewing homework in class, and receiving lecture note handouts. While including the first two items in the survey was considered beneficial to the initial data-gathering phase of the study, it was believed using them as test variables would compromise the overall learning objectives of the class. In other words, class lectures and going over the homework were considered too important to use as a treatment variable, which would have resulted in their being eliminated from either a course section or class topic. Among the items students felt did not add to their learning experience was requiring homework to be turned in to the teacher during class. In the first part of the two-sequenced course students were required to hand in homework, so it was also deemed an interesting and pragmatic test variable. Finally, approximately $40 \%$ of the students also provided supplemental written information regarding additional processes that would enhance their ability to learn the material. There were close to 40 different types of responses, covering a broad range (e.g., "being able to eat and drink during class", "being able to use my notes during an exam"). The top three comments, in order, were: more in-class group-work, receiving homework answers in advance, and receiving a longer during-class break. It was decided the final test variable chosen would be in-class assignments (to be completed either independently or working with other students - student's choice).

In summary, after reviewing the statistical data and written responses, it was decided that three topic delivery tools would be integrated into the second sequenced course (Principles 2) and ultimately measured: Providing lecture note handouts at the start of class, use of in-class assignments, and requiring homework to be turned in.

Table 2: Student Perception of Effective Teaching Methods Survey Results Presented in Order (Highest Ranked Listed First)

\begin{tabular}{|c|c|c|}
\hline Presented in Order & Likert-Scale & Forced Rank Scale \\
\hline Top Five & $\begin{array}{ll}\text { - } & \text { Reviewing homework in class } \\
\text { - } & \text { Lecture note handouts } \\
\text { - } & \text { e-mail availability of professor } \\
\text { - } & \text { Opportunity to ask questions in class } \\
\text { - } & \text { Class lectures }\end{array}$ & $\begin{array}{ll}\text { - } & \text { Class lectures } \\
\text { - } & \text { Reviewing homework in class } \\
\text { - } & \text { Lecture note handouts } \\
\text { - } & \text { Completing homework assignments }\end{array}$ \\
\hline Bottom Five & $\begin{array}{ll}\text { - } & \text { Working with other students out of class } \\
\text { - } & \text { Requiring homework to be turned in } \\
\text { - } & \text { Student tutoring facility } \\
\text { - } & \text { Required attendance } \\
\text { - } & \text { Homework check points }\end{array}$ & $\begin{array}{ll} & \left(1^{\text {st }} 4 \text { were tied }\right) \\
\text { - } & \text { Requiring homework to be turned in } \\
\text { - } & \text { Student tutoring facility } \\
\text { - } & \text { Instructor office hours } \\
\text { - } & \text { Course Luminus postings } \\
\text { - } & \text { Required attendance }\end{array}$ \\
\hline
\end{tabular}

\section{Second-phase: Embedded Test Questions}

Test 1

For Test 1 material, both sections of the course surveyed were taught using the same methods. Delivery of certain topics (such as job order costing and related journal entries and cost accumulation) required students to participate in in-class assignments. In addition, they received lecture note handouts (HO's) at the beginning of each class for those topics. While the students completed the assignments the instructor walked around the room, proactively observing students' work and was available to answer questions. A review of the first test results (Table 3 ) indicated that that both sections actually performed better on the topics where they did not receive handouts or inclass assignments. As expected, students had more difficulty with the quantitative questions, but the fact that the supplemental treatments did not improve test scores was counter to both what the students had indicated on the survey and the teacher's prediction. The somewhat surprising results set the stage for planning the delivery of the second round of topics. 
Table 3: Results from the First Test

Both Sections Received Same Treatment

(\% of Questions Answered Wrong)

\begin{tabular}{|l|c|c|}
\hline & $\begin{array}{c}\text { Topics for which students had in-class } \\
\text { assignments \& lecture note handouts }\end{array}$ & Topics with no variable delivery aides \\
\hline Quantitative Q's & $29.5 \%$ & $22.5 \%$ \\
\hline All questions & $25.2 \%$ & $17.05 \%$ \\
\hline
\end{tabular}

\section{Test 2}

In an attempt to gather more information and further isolate which tools may be affecting learning, material delivery adjustments were made for the next series of topics. For the first two topics, the use of handouts would be varied between the sections. For the third topic, students in both sections would be required to hand in a copy of their homework to the instructor. The results (Table 4) indicate there may have been some value to providing handouts for the Cost Allocation topic between sections, but within sections the results were contradictory. In addition, Section One performed substantially better on the topics for which they received handouts, while Section Two did not. Finally, in the subject matter where homework was required to be turned in, student's performance was the worst.

Table 4: Results from the Second Test

(\% of Questions Answered Wrong)

\begin{tabular}{|c|c|c|c|}
\hline Topic & Section 1 & Section 2 & Difference Between Sections \\
\hline $\mathrm{C}-\mathrm{V}-\mathrm{P}$ analysis & $\begin{array}{l}\text { No HO's } \\
26.2 \%\end{array}$ & $\begin{array}{l}\text { HO's } \\
26.1 \%\end{array}$ & $.1 \%$ \\
\hline Cost Allocation & $\begin{array}{l}\text { HO's } \\
13.9 \%\end{array}$ & $\begin{array}{c}\text { No HO's } \\
15.4 \%\end{array}$ & $5.4 \%$ \\
\hline Difference within sections & $12.3 \%$ & 10.7 & \\
\hline Cost Management Decision Making & $\begin{array}{c}\text { Required Homework } \\
30.9 \%\end{array}$ & $\begin{array}{c}\text { Required Homework } \\
35.4\end{array}$ & \\
\hline
\end{tabular}

For comparative purposes, the results reflect an adjustment for the average test score difference from the first test between the two sections.

Test 3

Based on the second set of results (Table 5), and because so many of the current students (Principles 2) expressed a strong desire to receive the handouts, it was decided to again include this as a delivery-aide variable. The results were once again conflicting between the sections but were consistent with the Test 2 score results: Section One performed substantially better on the topics for which they received handouts, while Section Two did not.

Table 5: Results from the Third Test

(\% of Questions Answered Wrong)

\begin{tabular}{|l|c|c|c|}
\hline \multicolumn{1}{|c|}{ Topic } & Section 1 & Section 2 & Difference \\
\hline Budgeting & HO & No HO's & $.4 \%$ \\
\hline Capital Budgeting & $17.1 \%$ & $16.7 \%$ & $4.4 \%$ \\
\hline Difference & No HO's & HO's & \\
\hline
\end{tabular}

For comparative purposes, the results reflect an adjustment for the average test score difference from the first test between the two sections. 


\section{DISCUSSION}

The goal of this research was to utilize Total Quality Management techniques to help understand the effect of various course delivery mechanisms on student learning in the introductory accounting classes. The two introductory classes, Principles of Accounting 1 and 2, are required courses for all business majors at the college where the study took place. This creates a particular challenge, because the courses are quantitative in nature, yet the audience is mixed (approximately half of the students have declared non-quantitative majors). Assurance of learning has been popularized in recent years due to promulgation by accrediting boards, in particular the top business school accrediting board, the AACSB. Assurance of learning asks that educators engage in a process which seeks to improve student learning, understanding that the measured results will be an unknown, and not necessarily what the instructors might predict or logic would seem to dictate. This viewpoint was central to engaging in the current study, as the nature of this research would be exploratory at every step. Although an initial research plan was developed, it was understood that adjustments would be required after each data-gathering phase, based on analysis of the most recent results.

While the tenets of Assurance of Learning support the fact there would be inherent value in conducting the research presented in this study, there were also some interesting and unexpected results. The study was twophased. Students were initially asked to self-report on which delivery-aide variables helped them to best learn the material. While it was certainly interesting to ascertain which tools the students felt were important to their learning, the second phase would provide an opportunity to determine if their opinions could be supported by measurable results. Although the resulting data was objectively analyzed by examining the statistical results, the subjective (albeit seasoned), judgment of the researchers also needed to be integrated into the decision process when deciding which treatment variables would be used for each topic and section. Student's indicated on the survey that receiving lecture note handouts (so they did not need to write them out themselves) would improve their learning. This variable was included in all three parts of the measurement phase. The overall results are inconclusive, however, there is some indication that the students in Section One may have benefited from receiving lecture note handouts, yet for Section Two students, receiving lecture note handouts may have actually been detrimental. Aside from convenience, a potential benefit to students of receiving the notes is that it frees up their time to listen more closely as the instructor provides supplemental information and examples. The focal point for the student can then become recording interpretive notes, versus the basic ones. On the other hand, certain students may benefit from not receiving the notes, as material comprehension may be reinforced when students are responsible for manually writing or typing the notes. Additionally, the manner in which students learn is so very individual (Levine, 2002) that it is possible, for the current study, that the average cognitive learning style for each of the two sections was different.

Students also indicated in the survey that they did not feel requiring homework to be turned in added to their learning. An interesting aspect to this assertion is that the college where the research took place does in fact require Principles 1 students to turn in their homework. The department believes this will encourage the students to complete the assignments ahead of class and that there is a direct relationship between homework completion and success in the class. In the end, the measured results from the current study seemed to support the students' opinion and may be cause for the department to reconsider the requirement. Reflecting anecdotally on the results, which were counter to anticipated results, one explanation may be that students were turning in their original work (versus a copy) and therefore did not have it available for subsequent review.

Finally, in the first set of topics, in-class assignments were completed in the same subject areas where lecture note handouts were provided. This process involved the teacher individually assisting students while they completed assignments. Although this required a considerable effort on the part of the instructor (because the same information is being explained multiple times, versus just once to the class as a whole) it was anticipated the individual attention would prove advantageous. However, there was no indication this treatment provided any benefit, and perhaps being put on the spot to solve a problem with a time constraint proved discouraging to students. In the end, the delivery of Test 1 material was supplemented with two treatments (lecture note handouts and in-class assignments) so it is difficult to conclude on either one completely independently. 


\section{LIMITATIONS AND IMPLICATIONS FOR FUTURE RESEARCH}

There are several limitations that may have impacted the results of this study. From a theoretical standpoint, it remains controversial as to whether students should be regarded as customers and empowered as such. From a practical standpoint, while the nature of the research required delivery-aid treatments to be varied between sections and chapters, the results may be somewhat reflective of the fact class makeup and chapter topics are different, and there was limited time between the tests and the need to adjust pedagogy for delivery of the next set of topics. Third, the data collected for the first part of this research was based on asking respondents to self-report, versus a more objective measure. Finally, even though demographics indicated the sample populations were similar, the exact sample was not the same. The results may have been different if the sample populations were identical.

\section{CONCLUSION}

Traditionally, the teacher has been viewed as knowing best what mechanisms will result in maximizing student learning. TQM philosophy shifts some of that responsibility to the student. This research contributes to pedagogical literature by combining TQM philosophy and assurance of student learning in the examination of an entire cycle of Principles of Accounting and working towards "closing the loop". Although no conclusive, generalized assertions resulted from the current study, the process of analyzing the measurable results by reflection and contemplation was constructive and beneficial. Fortunately, the accreditation process and boards also recognize there is value in an iterative process, and the more information we have the better we can proceed with the future.

\section{AUTHOR INFORMATION}

Dr. Mary Ellen O'Grady Harvey is an Associate Professor of Accounting in the Anisfield School of Business of Ramapo College of New Jersey. Her research interests include application of ethics in business, management accounting, and pedagogy.

Susan Eisner is a Professor of Management in the Anisfield School of Business of Ramapo College of New Jersey. Her research interests include organizational behavior, managerial communication, managing workplace diversity (gender, generations), entertainment/media/arts management, business/government/society, career building, and pedagogy.

\section{REFERENCES}

1. $\quad$ Alreck, P. and R. Settle: 1985, The Survey Research Handbook, (Irwin, Homewood, IL).

2. Al-Shammari, M.: 2005, 'Assessing the Learning Experience in a Business Process Re-engineering (BPR) course at the University of Bahrain', Business Process Management Journal 11(1), 47-62.

3. Association to Advance Collegiate Schools of Business: 2006, 'Eligibility Procedures and Accreditation Standards for Business Accreditation'. Retrieved March 18, 2010 from

http://www.aacsb.edu/accreditation/business/standards.

4. Betters-Reed, B. L., M. R. Nitkin and S. D. Sampson: 2008, 'An Assurance of Learning Success Model: Toward Closing the Feedback Loop', Organization Management Journal 5(4), 224-240.

5. Brown, R. and G. Murti: 2003, 'Student Partners in Instruction: Third Level Student Participation in Advanced Business Courses', Journal of Education for Business 79(6), 85-89.

6. Casner-Lotto, J. and M. Wright: 2009, 'The Ill-Prepared U. S. Workforce'. Retrieved March 19, 2010 from http://www.conference-board.org/publications.

7. Durlabhji, S.G. and M.R. Fusilier: 1999, 'The Empowered Classroom: Applying TQM to College Teaching', Managing Service Quality 9(2), 110-115.

8. Gershon, M.: 2010, 'Choosing Which Process Improvement Methodology to Implement', The Journal of Applied Business and Economics 10(5), 61-69.

9. Lavoie, D. and A.J. Rosman: 2007, 'Using Active Student-Centered Learning-Based Instructional Design to Develop Faculty and Improve Course Design, Delivery, and Evaluation', Issues in Accounting Education 22(1), 105-118. 
10. Leigh, D.: 1995, 'The "Walk the Talk” Model: A Classroom Model that Works in Education', Quality Progress 28(11), 67-70.

11. Levine, M.: 2002, A Mind at a Time, (Simon \& Schuster Paperbacks, NY).

12. Manivannan, M. and K.S. Premila: 2009, 'Application of Principles of Total Quality Management (TQM) in Teacher Education Institutions', Journal of College Teaching \& Learning 6(6), 77-88.

13. Martell, K.: 2007, 'Assessing Student Learning: Are Business Schools Making the Grade?', Journal of Education for Business 82(4), 189-195.

14. McConnell, C., G. Hoover and G. Miller: 2008, 'Course Embedded Assessment and Assurance of Learning: Examples in Business Disciplines', Academy of Educational Leadership Journal 12(3), 19-34.

15. Meirovich, G. and E. Romar: 2006, 'The Difficulty in Implementing TQM in Higher Education Instruction', Quality Assurance in Education 14(4), 324-337.

16. Mundhenk, R.T.: 2005, 'Assessment in the Context of Accreditation", in K. Martell and T. Calderon (Eds.), Assessment of Student Learning in Business Schools: Best Practices Each Step of the Way Vol. 1, pp. 2742, (Association for Institutional Research, Tallahassee, FL).

17. Noguchi, J.: 1995, 'The Legacy of W. Edwards Deming', Quality Progress 28(12), 35-38.

18. Pakdil, F.: 2010, 'The Effects of TQM on Corporate Performance', The Business Review, Cambridge 15(1), 242-248.

19. Peters, M.H., R.B. Kethley and K. Bullington: 2005, 'Course Design Using the House of Quality', Journal of Education for Business 80(6), 309-313.

20. Phillips, B.J. and F. Phillips: 2007, 'Sink or Skim: Textbook Reading Behaviors of Introductory Accounting Students', Issues in Accounting Education 22(1), 21-44.

21. Potocki, K., R. Brocato and P. Popick: 1994, 'How TQM Works in a University Classroom', Journal for Quality and Participation 17(1), 68-74.

22. Ross, J. E.: 1995, Total Quality Management, $2^{\text {nd }}$ edition (St. Lucie Press, Delray Beach, Fl).

23. Sakthivel, P. B. and R. Raju: 2006, 'An Instrument for Measuring Engineering Education Quality from Students' Perspective', The Quality Management Journal 13(3), 23-34.

24. Stivers, B. and J. Phillips: 2009, 'Assessment of Student Learning: A Fast-Track Experience', Journal of Education for Business 84(5), 258-262.

25. Venkatraman, S.: 2007, 'A Framework for Implementing TQM in Higher Education Programs', Quality Assurance in Education 15(1), 92-112.

26. Walker, H.: 1995, 'Texas Instruments' and Iowa State University's Experience with the University Challenge Program', Quality Progress 28(7), 103-106.

27. Zhu, F. X. and D. McFarland: 2005, 'Towards Assurance of Learning in Business Programs: Components and Measurements', Journal of American Academy of Business 7(2), 69-72. 


\section{NOTES}

